\title{
The Role of Digital Finance to Strengthen Financial Inclusion and the Growth of SME in Indonesia
}

\section{Atina Shofawati}

Faculty of Economics and Business, Islamic Economics Department, Jl. Airlangga 4, Universitas Airlangga, Surabaya, Indonesia

\section{Abstract}

At this era, innovation in technology is one of the key success factor for business to strengthen the maturity life of product life cycle, included financial industry. Nowadays the need for speed in delivery of product or services included in financial services especially Islamic Financial Services is very important. Indonesia which have the unique topography which consist of many islands need the speed of product or service delivery especially for the Small and Medium Enterprise (SME) financing which is the fundamental of economy in Indonesia. This paper have purpose to describes the

Corresponding Author:

Atina Shofawati

atinashofawati@yahoo.com

Received: 10 February 2019

Accepted: 14 March 2019

Published: 28 March 2019

Publishing services provided by

Knowledge E

(c) Atina Shofawati. This article is distributed under the terms of the Creative Commons

Attribution License, which permits unrestricted use and redistribution provided that the original author and source are credited.

Selection and Peer-review under the responsibility of the ICIEBP Conference Committee.

\section{G OPEN ACCESS} role of Digital Finance to Strengthen Financial Inclusion and the Growth of SME in Indonesia.This paper uses qualitative method. The result of this research is describe the model of the role of Digital Finance to Strengthen Financial Inclusion and the Growth of SME in Indonesia.

Keywords: Digital Finance, Financial Inclusion, Growth of SME, Indonesia.

\section{Introduction}

According to the theory of product life cycle, every business enter four steps consist of introduction, growth, maturity and decline. One of strategy to strengthen maturity stage is through innovation. Innovation in the financial service business is known as digital finance. Digital finance give more easily access for business especially for the small and medium enterprise (SME) in Indonesia. Small and Medium Enterprise (SME) is fundamental of economy in Indonesia, so the role of SME is very important to increase the growth of Indonesian economy.

Article of Ozili (2018) provides a discussion on some issues associated with digital finance - an area which has not been critically addressed in the literature. Digital finance and financial inclusion has several benefits to financial services users, digital finance providers, governments and the economy; notwithstanding, a number of issues 
still persist which if addressed can make digital finance work better for individuals, businesses and governments. The digital finance issues discussed in this article are relevant for the on-going debate and country-level projects directed at greater financial inclusion via digital finance in developing and emerging economies (Ozili, 2018).

Ozili (2018) examines the impact of digital finance for financial inclusion and financial system stability. Focussing on digital finance, this article provides a discussion on digital finance and explores the impact of digital finance for financial inclusion and financial system stability - an issue which has not been addressed in the literature. At a conceptual level, the discussions also address the benefits and risks of digital finance, digital financial inclusion and financial inclusion. Since 2010, the G-20 and the World Bank have led the initiative for increased financial inclusion in developing countries to help reduce poverty levels in developing and emerging economies (GPFI, 2010) in (Ozili, 2018). Today, the relevance of digital finance and financial inclusion for poverty reduction and economic growth is attracting the attention of policy makers and academics, largely because of the number of issues that persist which if addressed can make digital finance work better for individuals, businesses, governments and the economy. Digital finance and financial inclusion have several benefits to financial services users, digital finance providers, governments and the economy such as increasing access to finance among poor individuals, reducing the cost of financial intermediation for banks and Fintech providers, and increasing aggregate expenditure for governments. Notwithstanding its benefits, digital finance and financial inclusion have not adequately permeated vast segments of the population (G20 Summit, 2013) in (Ozili, 2018), which suggests an existing gap between the availability of finance, its accessibility and use. One area where the disparity is quite pervasive and is receiving increased attention particularly among Fintech providers is digital financial inclusion, financial data inclusion and digital finance. The relationship between these, and the issues they pose for financial inclusion have received very little attention in the literature. Also, Fintech providers can promote economic growth during good economic times by increasing the volume of financial transactions in the financial system, although, it is still unknown whether Fintech providers and their activities can exacerbate economic crises during bad economic times. This issue is also discussed in this article. (Ozili, 2018).

According to Michelle (2016) Digital financial services is vital to the public as it boosts security for their cash and it's more convenient compared to keeping money at home traveling with the money. However, the provision of digital finance involves the participation of different players such as banks/financial institutions, mobile network operators, financial technology providers, regulators, agents, chains of retailers and clients. Digital 
finance mechanisms also need improvement of infrastructures to make the services user-friendly, secure, and costeffective manner. The research of Michelle (2016) aimed at determining digital finance effect digital finance on financial inclusion in banking industry in Kenya (Michelle, 2016). Digital finance has been internationally regarded as an adequate means of providing opportunities to promote financial inclusion through reduction of costs of providing these services (Asian Development Bank, 2016) in Michelle (2016). Advanced account administrations are an inexorably turning into an essential part of the nexus amongst improvement and money related consideration. The utilization of computerized money related administrations has become essentially as of late among numerous individuals who have practically zero past involvement with formal monetary administrations (Villasenor, Darrell \& Lewis, 2015) in (Michelle, 2016).

The expansion of digital payment platforms has offered the opportunity to link poor people with providers of savings, credit, and insurance products (Radcliffe \& Voorhies, 2012) in (Michelle, 2016). Further, advanced account administrations developments and business sector improvements have opened open doors for lower-salary individuals with deficient money related administration choices (McKee, Kaffenberger \& Zimmerman, 2015) in (Michelle, 2016).

According to Ketterer (2017), since the end of the great crisis of 2007-10, the financial services industry began a process of accelerating change. New business models based on convergent technological developments are challenging the status quo of a longestablished and traditional industry. The purpose of this document is to consider the latest developments in the financial services industry and to discuss how they might affect the ability for firms-particularly small- and medium-sized enterprises (SMEs) and individuals to access financing. It concludes that the transformative developments in the financial services industry will most likely improve and expand access of firms and individuals to finance, as well as increase formalization and financial inclusion. Some hurdles and risks that may hamper and/or delay the process are identified: the reaction of the industry incumbents, the lack of appropriate and timely regulation, the lack of access to good-quality and affordable digital connectivity (broadband access), and the unforeseen and seriously disruptive changes that might come from the payments space. To confront these risks, the public sector must define a set of proper and timely responses. The strategy for public interventions must be defined based on a deep understanding of the forces that are driving the change

Beck (2016) documents and discusses recent advances in measuring financial inclusion and takes stock of the literature on the impact of financial inclusion on individual and aggregate welfare. Theory and empirical evidence has shown that financial deepening 
(more than financial inclusion) has a critical impact on structural transformation and poverty alleviation in developing countries. Among different financial services, expanding access to payment services seems to provide the biggest and most immediate impact on individual welfare. Financial innovation, including new delivery channels, new products and new intermediaries, have helped increase financial inclusion dramatically in some countries over the past decade, but also has repercussions for how we measure financial inclusion. The recent progress in measuring and tracking financial inclusion has been important for policy analysis and the setting of targets. However, caution is advised in over-interpreting headline indicators (Beck, 2016).

Based on the above explanation from the previous research can be concluded that there are any relationship between Digital Finance to Strengthen Financial Inclusion and the Growth. This paper emphasize the role Digital Finance to Strengthen Financial Inclusion and the Growth of SME in Indonesia. Small and Medium Entreprise (SME) in Indonesia have significant role to strengthen the economy of fundamental of Indonesia. Most of SME is have diffuclty to access the financing from the commercial bank so the availability of digital finance can strengthen the financial inclusion to increase the growth of SME in Indonesia. Problem statement of this research is To examine The Role of Digital Finance to Strengthen Financial Inclusion and the Growth of SME in Indonesia.

\section{Literature Review}

\subsection{Digital finance: Concept and benefits}

\subsubsection{Concept}

From a practitioner's viewpoint, digital finance is financial services delivered through mobile phones, personal computers, the internet or cards linked to a reliable digital payment system. Similarly, a McKinsey report identify digital finance as "financial services delivered via mobile phones, the internet or cards" (see Manyika et al, 2016: p.4) in (Ozili, 2018). According to Gomber et al (2017) in (Ozili, 2018), digital finance encompasses a magnitude of new financial products, financial businesses, finance-related software, and novel forms of customer communication and interaction - delivered by FinTech companies and innovative financial service providers. While there is no standard definition of digital finance, there is some consensus that digital finance encompasses all products, services, technology and/or infrastructure that enable individuals and companies to have access to payments, savings, and credit facilities via the internet (online) without the need to visit a bank branch or without dealing directly with the financial service provider. 
In Europe, the internet has emerged as a widely recognised distribution channel for the banking industry, and all traditional banks as well as new players, are discovering its effectiveness compared with other channels (Barbesino, Camerani and Gaudino, 2005) in (Ozili, 2018). The goal of financial services made available via digital platforms is to contribute to poverty reduction and to contribute to the financial inclusion objectives of developing economies (United Nations, 2016) in (Ozili, 2018). Ideally, there are three key components of any digital financial service: a digital transactional platform, retail agents, and the use by customers and agents of a device - most commonly a mobile phone - to transact via the digital platform (CGAP, 2015) in (Ozili, 2018).. To use digital financial services (DFS), the DFS user will have an existing bank account which they own (or third-party accounts with approved permission to use them) and should have available funds (or overdraft) in their accounts to make cash payments (outflows) or to receive revenue (cash inflow) via digital platforms including mobile devices, personal computers or the internet (Ozili, 2018).

\subsubsection{Digital finance}

This refers to arrangement of some blend of money related and installment benefits that are conveyed and oversaw utilizing portable or Web advances and a system of specialists (Peake, 2012) (Michelle, 2016). As per the World Bank (2015) in (Michelle, 2016)), computerized money related administrations allude to the utilization of advanced innovations (web, versatile correspondence innovation) to get to monetary administrations and execute budgetary exchanges. Thus, digital financial services generally refer to the far-reaching technologies available to perform financial services from a widespread range of providers to an extensive category of recipients. This is possible by use of digital remote means including e-money, mobile money, card payments, and electronic funds transfers (Asian Development Bank, 2016) in (Michelle, 2016). Computerized Financial Services (DFS) are basically about sparing cash, getting to credit and protection, and performing exchanges through advanced channels like cell telephones, cards, PCs, tablets, et cetera (Martin et al., 2016) in (Michelle, 2016). Digital financial payment products allow users to access funds from far-flung business people, relatives and friends during moments of crisis, reducing the likelihood that they will fall into poverty, to begin with (Klapper, ElZoghbi \& Hess, 2016) in (Michelle, 2016). Advanced budgetary administrations, for example, versatile cash furnish people with more prominent accommodation, protection, and, as a rule, improved security contrasted with putting away money at home or going with money (Villasenor, Darrell \& 
Lewis, 2015) in Michelle (2016). Computerized back likewise assumes an essential part for little organizations as it gives them access to fund alongside secure budgetary items, electronic installment frameworks and an opportunity to assemble a money related history (Mujeri, 2015) in (Michelle, 2016).

\subsubsection{Benefits}

Digital finance has some benefits. For instance, digital finance can lead to greater financial inclusion, expansion of financial services to non-financial sectors, and the expansion of basic services to individuals since nearly $50 \%$ of people in the developing world already own a mobile phone (WorldBank, 2014) in (Ozili, 2018).Two, digital finance has the potential to provide affordable, convenient and secure banking service to poor individuals in developing countries (CGAP). Recent improvement in the accessibility and affordability of digital financial services around the world can help millions of poor customers move from cash-based transactions to formal digital financial transactions on secured digital platforms (CGAP). Three, digital finance promises to boost the gross domestic product (GDP) of digitalised economies by providing convenient access to diverse range of financial products and services (and credit facilities) for individuals as well as small, medium and large businesses, which can boost aggregate expenditure thereby improving GDP levels. Digital finance can also lead to greater economic stability and increased financial intermediation, both for customers and for the economy where they and their families reside. Four, innovation in digital finance can have long-term positive effects for banking performance. Scott, Van Reenen and Zachariadis (2017) in (Ozili, 2018) examine the impact on bank performance of the adoption of SWIFT, a network-based technological infrastructure and set of standards for worldwide interbank telecommunication. They examine 6848 banks in 29 countries in Europe and the U.S. They Find that the adoption of SWIFT (i) has large effects on profitability in the longterm; (ii) these profitability effects are greater for small banks than for large banks; and (iii) exhibits significant network effect on performance. Five, digital finance also benefits governments by providing a platform to facilitate increase in aggregate expenditure which subsequently generates higher tax revenue arising from increase in the volume of financial transactions (Manyika et al, 2016) in (Ozili, 2018).. Six, digital finance has benefits to financial and monetary system regulators because full-scale digital finance adoption can significantly reduce the circulation of bad (or fake) money, etc. Other benefits of digital finance to customers includes greater control of customers' personal finance, quick financial decision making, and the ability to make and receive payments 
within seconds (Ozili, 2018). In conclusion, digital finance should improve the welfare of individuals and businesses that have formal bank accounts and have funds in their bank accounts to complete multiple financial transactions. However, the expected benefits of digital finance can only be fully realised if the cost of providing digital financial services is negligible or zero (Ozili, 2018).

\subsection{Digital financial inclusion: Concept and benefits}

\subsubsection{Concept}

The CGAP defines digital financial inclusion as "digital access to, and the use of, formal financial services by the excluded and underserved population" (CGAP, 2015) in (Ozili, 2018).. Currently, innovative digital financial services via mobile phones and similar devices have been launched in at least 80 countries (GSMA, 2014) in (Ozili, 2018), to encourage millions of poor customers to exclusively use digital financial services rather than cash-based transactions. The process of digital financial inclusion begins with the assumption that the excluded and/or underserved population have some sort of formal bank accounts and need digital access to enable them to carry out basic financial transactions remotely. If the excluded and underserved population understand and can be persuaded about the intended benefits of digital financial inclusion, an effective digital financial inclusion program should be suited to meet needs of the excluded and underserved population and should be delivered responsibly at a cost that is sustainable to providers and affordable to customers (Ozili, 2018).

\subsubsection{Financial inclusion}

This refers to the access and applying set of adequate financial services by households and firms is essential for advancement as it can help poor family units enhance their lives while likewise impelling financial movement (IDB, 2015) in (Michelle, 2016). Budgetary incorporation likewise implies that formal money related administrations, for example, store and bank accounts, installment administrations, credits and protection are readily available to consumers and that they are actively and effectively using these services to meet their specific needs (Klapper, El-Zoghbi \& Hess, 2016) in (Michelle, 2016). Financial deepening on the other hand is the change or increment in the pool of monetary administrations that are custom fitted to the necessity of all levels in the general public (Bharat, 2014). The impact of expanding financial inclusion goes well beyond financial 
deepening and spans over a wide range of development goals (IDB, 2015) in (Michelle, 2016).

\subsubsection{Benefits}

Digital financial inclusion has some benefits. Digital financial inclusion promises to help banks lower costs by reducing queuing lines in banking halls, reduce manual paperwork and documentation and to maintain fewer bank branches (IFC, 2017; Manyika et al, 2016) in (Ozili, 2018). With digital financial inclusion, large number of depositors can easily switch banks within minutes; forcing banks to provide quality services or risk losing depositors to rival banks. For financial and monetary system regulators, digital financial inclusion also helps to reduce the amount of physical cash in circulation and is instrumental in reducing high inflation levels in developing and poor countries (GPFI, 2016) in (Ozili, 2018). Digital financial inclusion can improve the welfare of individuals and businesses that have a reliable digital platform with which to access funds in their bank accounts to carry out financial transactions (CGAP, 2015) in (Ozili, 2018). The expected benefits of digital financial inclusion can be fully realised if the cost of obtaining a digital transactional platform by poor individuals is negligible or low, where a digital transactional platform refers to mobile phones, personal computers and related devices (Ozili, 2018).

\subsection{Financial inclusion: Concept and benefits}

\subsubsection{Concept}

According to a United Nations Report, financial inclusion is the sustainable provision of affordable financial services that bring the poor into the formal economy (United Nations, 2016) in (Ozili, 2018. Financial inclusion may also be defined as the use of formal financial services by the poor (Beck, Demirgüc Kunt \& Levine, 2007; Bruhn and Love, 2014) in (Ozili, 2018). Financial inclusion involves increasing the number of (mostly poor) individuals that have access to formal financial services mainly through having formal bank accounts, which contributes to poverty reduction and economic growth. With greater financial inclusion, individuals who were previously financially excluded will be able to invest in education, save and launch businesses, and this contributes to poverty reduction and economic growth (Beck, Demirgüc-Kunt, and Levine, 2007; Bruhn and Love, 2014) in (Ozili, 2018).. An inclusive financial system should provide 
opportunities for all people, particularly the poor, to access and move funds, grow capital, and reduce risk (Ozili, 2018).

\subsubsection{Benefits}

Financial inclusion has several benefits for poor households. It provides low-income individuals with the possibility to save for the future which fosters stability in personal finance, and a high level of use of bank deposits which contributes to securing a more stable deposit base for banks distressed times (Han and Melecky, 2013) in (Ozili, 2018). Greater financial inclusion can also provide poor households with opportunities to build savings, make investments and access credit (Ellis, Lemma, and Rud 2010) in (Ozili, 2018). Financial inclusion also enables them to handle income shocks over unforeseen emergencies such as illness or loss of employment (Collins et al., 2009) in (Ozili, 2018).. Also, financial inclusion has positive effects for financial stability by reducing procyclicality risk; a substantial increase in the number of small savers via greater financial inclusion would increase both the size and stability of the deposit base of banks which would reduce banks' dependence on "non-core" financing, which tend to be more volatile during a crisis (Khan, 2011) in (Ozili, 2018).), thus improving banking system stability. Also, low-income groups are relatively immune to fluctuation in economic cycles and including them in the financial sector will improve the stability of the deposit and loan bases in the financial system. Hannig and Jansen (2010) in (Ozili, 2018).show that financial institutions catering to the lower end individuals tend to survive through macrocrises well and help sustain local economic activity. Additionally, Prasad (2010) in (Ozili, 2018). also observes that the lack of adequate access to credit for small and medium-size enterprises and small-scale entrepreneurs has adverse effects on overall employment growth since these enterprises tend to be much more labour intensive in their operations. Also, greater levels of financial inclusion can facilitate increased participation by different sectors of the economy in the formal financial system because, as the share of the formal financial sector increases, it strengthens the case for the use of interest rate as a key policy tool for macroeconomic stability, which has positive effects for economic growth (Cecchetti and Kharroubi, 2012) in (Ozili, 2018). According to Dev (2006) in (Ozili, 2018), financial inclusion can be viewed both as a business opportunity and social responsibility when self-help group movements and microfinance institutions participate in inclusion programs, because these two agents are important to improve financial inclusion. 


\subsection{Fintech providers: Concept and benefits}

\subsubsection{Concept}

According Ozili (2018) the term 'Fintech' denotes 'financial technology' and is defined as the delivery of financial and banking services through modern technological innovation led by computer programs and algorithms. A Fintech provider, on the other hand, is defined as an individual or company that uses a technology platform, whether online or offline, to provide new financial services or to improve the delivery of existing financial services. Ideally, a provider would qualify to be termed a Fintech provider if it uses technology (whether online or offline) to provide, or to improve, the delivery of financial services such that the number of hurdles between requesting for a financial service and receiving the financial service is significantly reduced for users of financial services. However, and in practice, the technology adopted by some self-identifying Fintech providers do not significantly reduce the hurdles that customers must go through between requesting for a financial service and receiving the financial service, which then cast doubts on whether these individuals or companies should be termed 'Fintech', and the debate about whether to de-classify such companies as 'Fintech' is still on-going in some countries.

Fintech companies play an important role in the digital finance economy. Fintech providers are emerging in the financial services sector to either compete with banks or to complement the functions of banks to their customers. In the real world, some Fintech companies provide financial services at a higher cost while the cost of obtaining financial services from banks is relatively lower but the lengthy process of waiting to obtain a loan from regulated banks is making customers turn away from bank providers to non-bank providers. For instance, a customer that walks into a bank on Monday requesting for $£ 70,000$ loan is not likely to obtain the full loan amount requested for on Monday, and this phenomenon is attributed to the fact that bank regulators and banks' internal risk management procedures require banks to spend a considerable amount of time to assess whether an individual qualify to receive a loan or not (Ozili, 2018).

Despite the high cost of obtaining financial services from nonbank providers, individuals and companies with low and/or volatile income still prefer to use the services of non-bank providers, many of whom are not currently regulated in emerging countries and in most African countries. Finally, Fintech companies are diverse, and their diversity largely depends on available technology whether online or offline. Examples of Fintech businesses are those that engage in quick checkcashing services, payday lending, and 
related services. Finally, the activities of Fintech providers can have implications for financial inclusion and stability (Ozili, 2018).

\subsubsection{Benefits}

According to Ozili (2018) there are benefits of doing business with Fintech providers. There are reasons why individuals would rely on Fintech providers even though federally insured banks can provide the same financial services to customers at lower costs than Fintech providers. One, Fintech providers can provide quicker financial services with a seamless process, making it easier for low income individuals to manage their financial obligations on a day to day basis. Two, Fintech providers do not handle deposits like banks which implies that Fintech providers will face fewer regulations (or will be unregulated in some countries) and the low regulatory burden they face makes it easier for Fintech providers to focus on improving their financial technology and intermediation function while reducing, where possible, to serve customers better. Three, Fintech providers can partner with traditional lending institutions which can help them reduce operational costs and improve the quality of their intermediation activities. Partnering with traditional lending institutions can help Fintech providers become sustainable over time, while the financial technology of Fintech providers can add value to the activities of the traditional lending institutions they partner with, particularly in 'process improvement' for their online lending business. Four, some Fintech providers have superior ability to provide instant emergency funds or loans in small amounts to individuals with low and poor incomes compared to banks and other lending institutions. This is because conventional banks and other lending institutions are not obliged to provide emergency funds to anyone, and any request for emergency funding at a conventional bank or lending institution must go through the usual credit risk assessment processes which may be too lengthy for individuals that need instant emergency funds. This puts some Fintech providers in abetter position to provide emergency funds in small amounts at higher interest rates to individuals with middle and low incomes. Five, there is the potential for technology to provide convenience. Fintech providers that operate via online platforms can electronically provide increased convenience to users by providing access to such services and making it available always from any location where the user or consumer can access the Internet. This enables Fintech providers to help customers to avoid having to travel to a banking hall to undertake financial transactions (Ozili, 2018). 


\subsection{Theory of financial innovations}

The theory of financial innovations was proposed by Silber (1983) in Michelle (2016) premised on the idea that benefit expansion of money related foundations is the key reason of financial inclusion (Li and Zeng, 2010) in (Michelle, 2016). The theory demonstrates that the primary thoughtsbehind the new innovations are the defects of the money related business sector, mostly the deviated data, office expenses and exchange costs (Błach, 2011) in (Michelle, 2016). According to the theory, financial related innovations can be very new resolutions or simply customary means whereby latest component of development has been offered, enhancing firms' liquidity as well as expanding quantity new applicants, due to their qualifications on the situation (lonescu, 2012) in (Michelle, 2016).

\subsection{Diffusion of innovation theory}

The Diffusion of Innovations (DOI) theory was proposed by Rogers (1995) in (Michelle, 2016) to explain the approach through which innovation can be passed via different ways over certain period among different users (Sarker \& Sahay, 2004) in (Michelle, 2016). DOI theory explores the ways in which innovative ideas are passed from one generation to the other. According to DOI theory, an innovation is conveyed through various channels continually among individuals of the same social beliefs (Echchab \& Hassanuddeen, 2013) in (Michelle, 2016). The dispersion of Innovation hypothesis looks at the rate at which new advancement are spreading, how the new development is spreading and reasons why it is spreading with a specific end goal to research the elements influencing the selection of new data innovation advancement (Monyoncho, 2015) in (Michelle, 2016)

\section{Methodology}

This study have Research Design employed descriptive qualitative research. A descriptive research design according to Lavrakas (2008) in (Michelle, 2016) posits that a descriptive study design is a non-experimental research designs across several disciplines to collect large amounts of survey data from a representative sample; sampled from the study population. Additionally, a descriptive research plan guarantees complete description of the situation, ensuring that there is minimum bias in the collection of data from the study population (Cooper \& Schindler, 2008). (Michelle, 2016) in Michelle 
(2016). This study conduct qualitative research based on literature review from the previous research and then create a model which describe model of the role of Digital Finance to Strengthen Financial Inclusion and the Growth of SME in Indonesia.

\section{Discussion}

\subsection{Effect of digital finance on financial inclusion}

Digital financial services are held out as key money related answers for enhancing monetary consideration (Buckley \& Malady, 2015) in (Michelle, 2016). The methodology of DFS has presented positive effect by initiating neighborhood and rustic economies through expanded cash dissemination, business development and work opportunities (European Investment Bank, 2014) in (Michelle, 2016)). Achieving financial inclusion requires bridging the gap between cash and digital payments (Dayadhar, 2015) in (Michelle, 2016)). Through digital financial services, poor households often need to accumulate sums of cash to invest in their micro-enterprises and to maintain precautionary cash to ensure that unexpected shocks. In addition, once customers are connected to a digital payment system, they are able to transfer money instantly and cheaply to friends, family and business collaborate (Radcliffe \& Voorhies, 2012) in (Michelle, 2016). Empirically, a study by Kama and Adigun (2013) in (Michelle, 2016) on financial inclusion in Nigeria, its challenges and the experiences of other jurisdictions found that deficient and wasteful innovation based offices by money related establishments, has restricted the accomplishment of critical extension in budgetary incorporation level in Nigeria. Bayero (2015) in (Michelle, 2016) inspected the relationship between the cashless economy approach and money related incorporation and uncovered that mindfulness, shopper/client esteem recommendation, and foundation had a solid noteworthy association with budgetary consideration while plan of action of monetary administration suppliers had an inconsequential association with money related incorporation. Andrianaivo and Kpodar (2011) in (Michelle, 2016) considered the relationship between data correspondence innovation, monetary incorporation, and financial development and found that the spread of cellular telephones reinforces the impact of money related consideration on monetary development, especially in nations where portable budgetary administrations grab hold.

According to Ketterer (2017), since the end of the great crisis of 2007-10, the financial services industry began a process of accelerating change. New business models based 
on convergent technological developments are challenging the status quo of a longestablished and traditional industry. The purpose of this document is to consider the latest developments in the financial services industry and to discuss how they might affect the ability for firms-particularly small- and medium-sized enterprises (SMEs)-and individuals to access financing. The Connectivity Markets and Finance Division (CMF) of the Inter-American Development Bank (IDB) looks at the factors that impede access to productive finance in the Latin American and Caribbean (LAC) region, and determines how to improve access through public policies and financial engineering. The overall thesis of this paper is that it seems plausible to think that the new business models of financial intermediation and capital markets organization, emerging from the adoption of convergent technologies, facilitate access to finance by SMEs and unbanked individuals, resulting in positive incentives for firms' formalization and financial inclusion. The following points support this view: New-entrant market lenders, with alternative intermediation models and advanced credit scoring techniques, are challenging traditional incumbent banks and pushing the financial services industry toward lowering lending spreads. They are also expanding the set of bankable firms and individuals. The use of ecommerce, e-payments, and other digital channels allows firms and individuals to create a credible and transmissible digital history or identity. These data can be fed into artificial intelligence-based credit score engines that deliver more accurate credit assessments. These improved processes reduce asymmetric information between borrowers and lenders, facilitating access to financing. Furthermore, the increased benefits of having a digital history or identity are driving more firms and individuals toward formalization and financial inclusion. New techniques and procedures to handle collateral, supported by blockchain-based registries, are making the use of collateral more efficient, cheaper, and more secure. This allows an expansion on the use of collateral and, hence, an enlargement of the firms that can access credit. More efficient, secure, and cheaper capital markets, organized around blockchain-based networks, will free up bank capital that can be reallocated toward the lending space. Other improvements in payments, reporting and compliance, insurance, trade finance, and other financial domains will result in a more efficient financial services industry.

\subsection{The drivers of change}

The first driver of change is the exponential growth of a set of technologies that are converging toward new business models that are challenging the modern-day financial services industry. The most important technologies for the dynamics of the financial 
services industry are: cloud computing, robotics, distributed ledger technologies (DLTs) (also known as blockchain), virtual currencies, biometrics, artificial intelligence and advanced analytics, the Internet of things, virtual-augmented reality, and advanced identity management methods. These technologies are powerful in stimulating challenge because they enable business models of entry that require very little investment. For example, the possibility of accessing computing as a service using cloud computing allows entrants or challengers to start their business with almost no capital expenditure. This is an example of a more general trend of acquiring resources and assets through pay-as-you-go models, which is based on advances in digital connectivity. The second driver is the change in customer preferences. Consumers had grown accustomed to their experience in other digital spaces (e.g., Google, Amazon, Facebook, Apple, AliBaba, Tencent). They now expect a satisfying digital experience and services that are free, personalized, and easy to use ("me-easy-free-now" customers). In exchange, customers are willing to give away their information. This new attitude poses a challenge to both incumbents and entrants to develop business models that can monetize customer information.1 The third driver of change is the set of new financial regulations put in place in the wake of the financial crisis (Ketterer, 2017)

\subsection{Changes in the financial services industry and access to financing}

This section explores the most important changes that are taking place in the financial services industry. It also lays out some hypotheses on how these changes might affect access to productive financing, focusing on their impact on SMEs (Ketterer, 2017).

1. The emergence of a new class of financial intermediaries will expand the range of firms and individual that can access financing.

The Marketplace Lender's Business Model Marketplace lenders (MPLs) are a new class of financial institutions whose business model is based on digital platforms that match borrowers and lenders directly online. In a most basic version of the model, a MPL posts a list of projects asking for funding on its online platform and waits for prospective lenders to submit their bids. Then, there is an algorithm (more or less sophisticated) that matches both sides of the market. Once the matching has taken place, the MPL receives an origination fee and a fee for servicing the loan. (Ketterer, 2017).

Market Segments The MPL industry emerged some ten years ago, focusing on market segments that were underserved by traditional incumbent banks, such as the lower segments of SMEs and unbanked individuals. Since then, MPLs have evolved in two 
directions: (i) moving up the ladder and increasingly competing with banks for the richer segment of medium firms, challenging the traditional incumbent banks "from below"; and/or (ii) setting up alliances and partnerships with traditional incumbent banks. Rotman, Carroll, and Liu (2015) in Ketterer (2017) discuss different types of competition between banks and MPLs. One of the most striking aspects of their work is the description of SMEs' access to credit in the United States, which resembles that of some lessdeveloped countries (Ketterer, 2017).

Financial inclusion has increasingly moved to the top of the policy agenda in many developing countries, reflected in several G20 statements (most recently in 2016 in Hangzhou), establishment of financial inclusion units in Central Bank and Ministries of Finance and specific financial inclusion targets. One important aspect of formulating policy goals, however, is the ability to measure progress in achieving these goals. Over the past decade, enormous progress has been made in measuring financial inclusion across the globe. At the same time, being able to measure financial inclusion has allowed us to gauge the progress due to financial innovation and policy interventions. Critically, as more evidence becomes available on what dimensions and aspects of financial inclusion are important for individual welfare and firm growth, data collection can be and has been adjusted accordingly. This paper takes stock both of the progress in measuring financial inclusion as well as the literature on the impact of financial inclusion on individual and aggregate welfare (Beck, 2016).

\subsection{The role of digital finance to strengthen financial inclusion and the growth of SME in Indonesia}

Financial inclusion is one strategy to eliminate or reduce poverty, but it is not the only strategy. Other strategies to tackle poverty include direct government intervention through the provision of welfare benefits and unemployment benefits; or through direct or indirect intervention by foreign governments, generous aids by philanthropists and charity organisations, among others. Poverty reduction via greater financial inclusion can be led by the public sector or the private sector or via joint coordination by the private and public sector (Ozili, 2018).

The private sector offers digital finance as a solution for greater financial inclusion. Private sector players such as Fintech and financial services companies can offer digital finance products and services to the poor and excluded population, to encourage them to participate in the formal financial sector via digital channels from their mobile phones. If the excluded population have digital banking credentials (such as online banking login 
password and other forms of digital access credentials), they can link their bank accounts to digital payment channels to perform basic financial transactions. Moreover, if the cost for access to digital finance is cheap, low-income and poor individuals will participate in the digital financial system, thereby having positive effects for financial inclusion (Ozili, 2018).

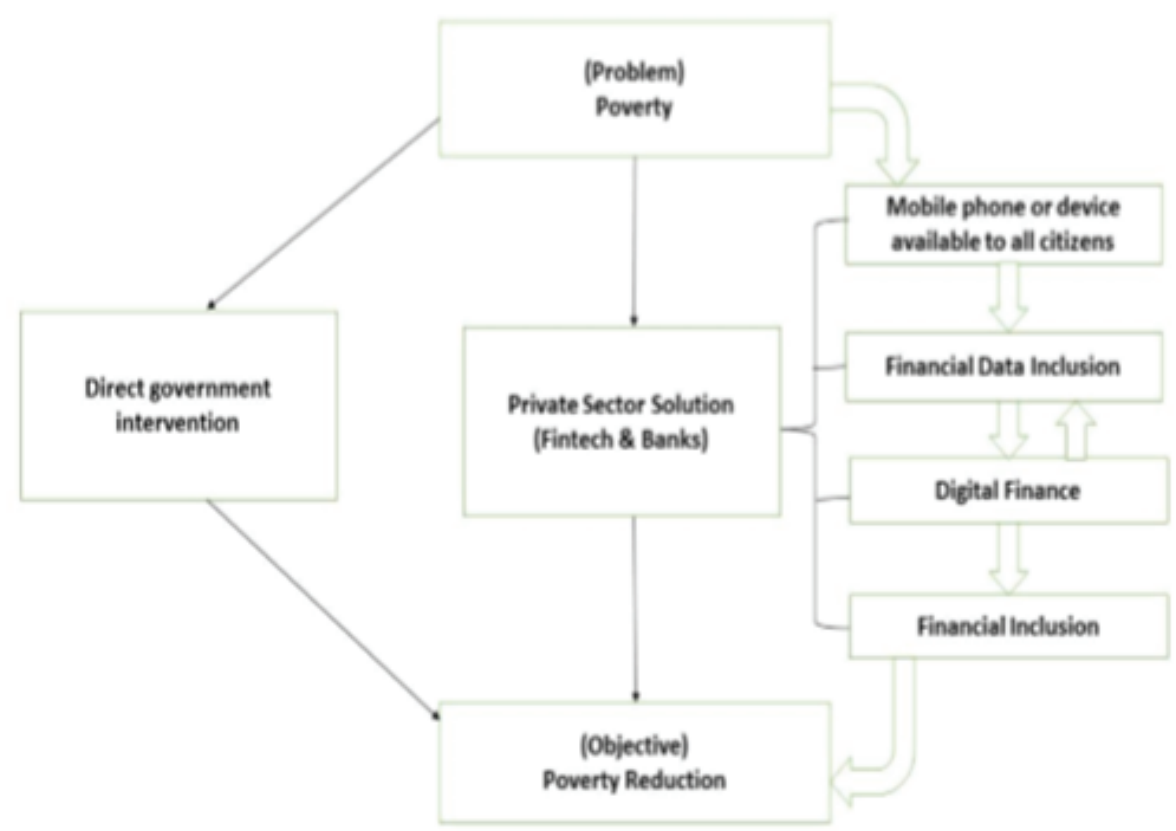

Figure 1: Framework to illustrate the role of government, FinTech, and banks in digital finance and financial inclusion (Source: Author - the Ozili Framework of Financial Inclusion (Ozili, 2018).)

Figure 1 shows the important role that the government, FinTech, and banks play in financial inclusion and poverty reduction. While there is no clear-cut theoretical framework underlying the distinction between financial data inclusion and financial inclusion, the idea underlying the differentiation of financial data inclusion and financial inclusion in Figure 1 is that full-scale financial data inclusion is needed for digital finance to achieve its full potential to achieve financial inclusion (Ozili, 2018).

Financial data inclusion involves merging the entire population's biometric information to their bank accounts while financial inclusion on the other hand involves increasing the number of (mostly poor) individuals that have access to formal financial services mainly via having formal bank accounts. Financial data inclusion is easier to achieve than financial inclusion, from a policy perspective. Merging individuals' biometric information to their bank accounts can achieve two objectives: it permits financial transactions via digital channels that can be verified and traced to individuals or firms, and it can help to 
monitor the income and demographic characteristics of users of digital financial services (Ozili, 2018).

If the excluded population are willing to actively participate in financial data inclusion by obtaining online banking login and other forms of digital access credentials, they will be able to use digital channels to carry out basic financial services, thereby leading to greater financial inclusion. If the excluded population do not wish to participate in financial data inclusion by refusing to have online banking login or other forms of digital access credentials, they will not be able to use digital channels to carry out basic financial services, thereby reducing financial inclusion. In this sense, full-scale financial data inclusion and the willingness of the population to participate in the digital space is essential for digital finance to achieve greater financial inclusion (Ozili, 2018).

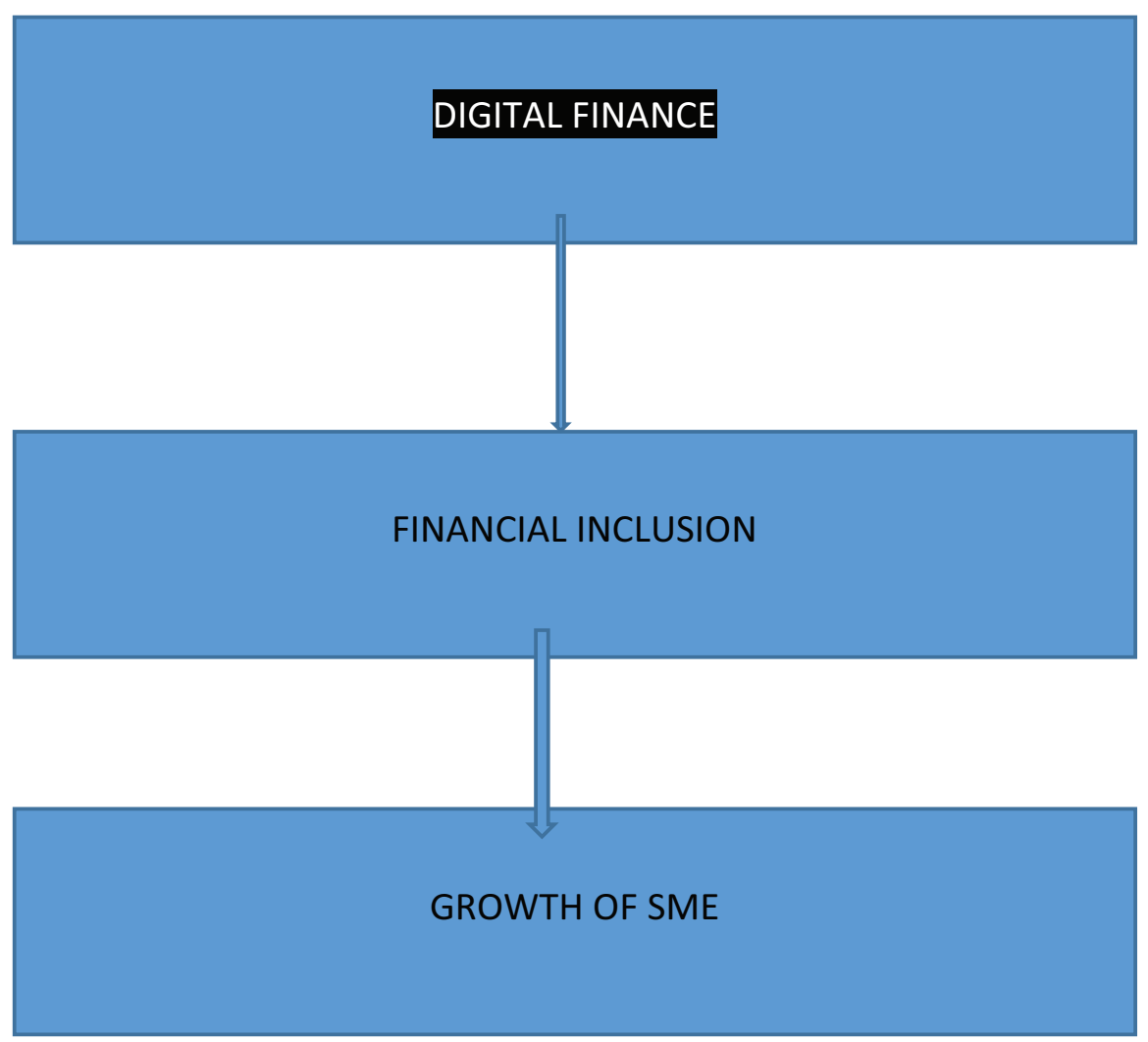

Figure 2: Role of Digital Finance to Strengthen Financial Inclusion and the Growth of SME in Indonesia.

The Role of Digital Finance to Strengthen Financial Inclusion and the Growth of SME in Indonesia is the availability of digital finance can create financial inclusion so the access for the financing is more easily especially for the SME which most of SME is not bankable. Based the financial inclusion based on digital finance SME can get capital and financing for the operational, investment and growth opportunity. This explanation can be seen at Figure 2. 


\section{Conclusion}

The Role of Digital Finance to Strengthen Financial Inclusion and the Growth of SME in Indonesia is the availability of digital finance can create financial inclusion so the access for the financing is more easily especially for the SME which most of SME is not bankable. Based the financial inclusion based on digital finance SME can get capital and financing for the operational, investment and growth opportunity.

\section{References}

[1] Agufa Midika Michelle. 2016. The Effect Of Digital Finance On Financial Inclusion In The Banking Industry In Kenya. A Research Project Submitted In Partial Fulfillment Of The Requirements For The Award Of The Degree Of Master Of Science In Finance, School Of Business, University Of Nairobi

[2] Juan Antonio Ketterer.2017. Digital Finance New Times, New Challenges, New Opportunities. IDB-Inter American Development Bank

[3] Peterson Kitakogelu Ozili.2018. Impact of Digital Finance on Financial Inclusion and Stability. University of Essex. Online at https://mpra.ub.uni-muenchen.de/84771/ MPRA Paper No. 84771, posted 24 February 2018 10:08 UTC

[4] Thorsten Beck. 2016. Financial Inclusion - measuring progress and progress in measuring. This paper was written for the Fourth IMF Statistical Forum "Lifting the Small Boats: Statistics for Inclusive Growth. Cass Business School, City, University of London, CEPR, and CESifo. 